\title{
O TRIBUNAL PARA A ANTIGA IUgOSLÁVIA NA FORMAÇÃo DA NORMA DA RESPONSABILIDADE INDIVIDUAL POR GRAVES VIOLAÇÕES DE DIREITOS HUMANOS: TENSÕES ENTRE DIREITOS HUMANOS E PRINCÍPIOS PENAIS LIBERAIS
}

\author{
THE INTERNATIONAL CRIMINAL TRIBUNAL FOR THE FORMER YUGOSLAVIA IN THE FORMATION \\ OF THE NORM OF INDIVIDUAL RESPONSIBILITY FOR SERIOUS HUMAN RIGHTS VIOLATIONS: \\ TENSIONS BETWEEN HUMAN RIGHTS AND LIBERAL CRIMINAL LAW PRINCIPLES
}

Renata Reverendo Vidal Kawano Nagamine*

Resumo: Neste artigo pretendeu-se analisar como o Tribunal Penal Internacional para a antiga Iugoslávia concorreu para consagrar uma concepção de justiça global que toma o direito internacional penal como coextensivo aos direitos humanos. Nele, parte-se de um estudo da cientista política Kathryn Sikkink sobre a formação da norma da responsabilidade criminal individual por graves violações de direitos humanos para explorar as tensões entre princípios penais e normas de direitos humanos naquele que foi o primeiro tribunal penal internacional desde o Tribunal de Nuremberg. Para tanto, analisam-se as primeiras decisões do Tribunal para a antiga Iugoslávia, tomadas entre os anos 1995 e 2000, com foco nas formulações sobre crimes contra a humanidade e legalidade pelos juízes de primeira e segunda instâncias do Tribunal.

Palavras-chave: Direitos humanos. Jurisdição internacional penal. Crimes contra a humanidade. Legalidade.

\begin{abstract}
This article it was aimed to analyze how the International Criminal Court for the former Yugoslavia (ICTY) concurred to consecrate a conception of global justice that takes international criminal law as coextensive with human rights. It departs from a study of the political scientist Kathryn Sikkink on the formation of the criminal individual responsibility norm for serious human rights violations to explore the tensions between criminal law principles and human rights norms in that which has been the first international criminal tribunal since Nuremberg. For this, I analyze the first ICTY decisions, most precisely, those taken from 1995 to 2000 focusing on the formulations about crimes against humanity and legality by the Trial and Appeal Chambers judges.

Keywords: Human rights. International criminal jurisdiction. International criminal law. Crimes against humanity. Legality.
\end{abstract}

\footnotetext{
Mestre em Direito Internacional pela Universidade de São Paulo; doutoranda em Direito Internacional pela Universidade de São Paulo; Pesquisadora colaboradora no Centro Brasileiro de Análise e Planejamento; Rua Morgado de Mateus, 615, Vila Mariana, 04015-051, São Paulo, São Paulo, Brasil; renagamine@gmail.com
} 


\section{Introdução}

Neste artigo pretendemos identificar e discutir algumas tensões ${ }^{1}$ entre direitos humanos e princípios penais liberais, com base na análise das primeiras decisões tomadas pelo Tribunal Penal Internacional para a antiga Iugoslávia (TPII), compreendendo o período de 1995 a 2000. Nosso argumento consiste em que, como primeira jurisdição internacional penal desde Nuremberg e o primeiro em uma "era de direitos", o Tribunal dá uma contribuição relevante para uma concepção específica de justiça, que toma as normas de direitos humanos e as normas internacionais penais como coextensivos. Entendemos que é por conta da prevalência dessa concepção de justiça que as tensões entre direitos humanos e princípio da legalidade prudencialmente equacionadas no TPII também têm lugar no Tribunal Penal Internacional (TPI), a despeito da definição longamente negociada e mais acabada dos crimes internacionais em seu Estatuto. Nossa preocupação de fundo consiste em que, nesse processo histórico de construção de determinada concepção de justiça global, os crimes contra a humanidade tornam-se mais e mais sinônimos de "crimes massivos", podendo facilitar aos Estados borrarem as linhas que os separam dos crimes comuns e legitimarem, por conseguinte, uma ampliação do seu poder de punir.

$\mathrm{O}$ artigo se insere, assim, em um debate consistente e profícuo, em curso na atual cena internacional mas ainda pouco destacado no Brasil, acerca da história das categorias e ideias em direito internacional e justiça global no pós-Segunda Guerra mundial. Esse debate tem engajado tanto scholars em direito internacional quanto historiadores, em geral, e historiadores do direito, em particular. $O$ direito internacional penal e os direitos humanos têm sido, nele, objeto preferencial e têm sido, por força dele, sujeitos a contínuas releituras e reelaborações.

Propomos adentrá-lo com uma análise das primeiras decisões do Tribunal para a antiga Iugoslávia, partindo do suposto de que um olhar para os entendimentos e as doutrinas elaborados pelo Tribunal possibilita identificar continuidades e descontinuidades na linha que o liga a Nuremberg. Optamos por efetuar essa discussão a partir dos crimes contra a humanidade por considerarmos que, na definição dos limites desses crimes e na nomeação de parâmetros para os delimitar, podemos vislumbrar traços da concepção de justiça que os informa e das potenciais restrições de princípios liberais que ela facilita e de princípios que têm fundamentado a legitimidade do poder punitivo estatal, justamente em nome da proteção dos direitos humanos, i.e., da humanidade do acusado.

No que segue, começamos, então, com uma revisão de The justice cascade, de Kathryn Sikkink, um estudo paradigmático em matéria de responsabilidade criminal individual por graves violações de direitos humanos. Na sequência, apresentamos o Tribunal para a antiga Iugoslávia e efetuamos uma incursão por suas primeiras decisões, com foco nos contornos dos crimes contra a humanidade delineados por ele. Nessa incursão, ressaltaremos a criatividade do Tribunal à luz do princípio da legalidade, com base em parâmetros estabelecidos pelo próprio Tribunal a propósito da

\footnotetext{
1 Entendemos por "tensões", aqui, conflitos entre normas jurídicas não solucionáveis em termos genéricos e abstratos envolvendo, no que nos interessa, graves violações de direitos humanos e princípio da legalidade. Empregamos o termo em lugar de "controvérsias" e "conflitos", que têm sentido jurídico próprio e não nos parecem dar conta dos atritos, das relações complexas e articulações, muitas vezes, difíceis entre os termos.
} 
criminalização no direito internacional, em decisão do caso Delalic. No final desse percurso, apresentamos algumas considerações finais.

\section{Da ideia à norma da responsabilidade criminal individual por graves violações de direitos humanos}

The justice cascade, da cientista política e professora de Harvard Kathryn Sikkink, é um estudo paradigmático para a discussão sobre responsabilidade criminal individual por graves violações de direitos humanos. Fruto de décadas de uma contínua e consistente reflexão sobre o tema, ele (re) constrói o processo de formação do que Sikkink denomina "norma da responsabilidade criminal por graves violações de direitos humanos", mapeando atores, ideias, estratégias e instituições que teriam concorrido para ele, em um arco temporal que se estende de finais dos anos 1960 a finais dos anos 1990.

Sikkink menciona três ideias subjacentes à "norma de justiça": graves violações de direitos humanos ${ }^{2}$ não são atos estatais legítimos e devem ser vistas como crimes; os indivíduos que as praticam devem ser processados; o acusado tem direitos e merece um julgamento imparcial, sendo este o aspecto que distingue os julgamentos de direitos humanos dos julgamentos políticos (SIKKINK, 2011, p. 13). Seu argumento consiste em que está emergindo um sistema descentralizado, mas interativo, de accountability por graves violações de direitos humanos, com enforcement fragmentado, pelo qual respondem, primeiro, as cortes nacionais. Esse sistema é interativo, porque as decisões tomadas em um nível têm efeito em outros níveis.

Grécia e Portugal foram os primeiros países a apurar a responsabilidade criminal de seus oficiais por graves violações de direitos humanos (SIKKINK, 2011, p. 31), mas, para o processo que se quer reconstruir, o caso mais importante é o argentino. Esse caso se tornou célebre pelos milhares de desaparecimentos forçados e pela inédita apropriação de bebês por um regime autoritário. Em meados dos anos 1970, começaram a se formar grupos locais na Argentina, como as Mães da Praça de Maio, que se articularam com ONGs internacionais (como a Anistia Internacional), a Comissão Interamericana de Direitos Humanos (CIADH) e o Governo dos Estados Unidos, formando uma rede transnacional de advocacy. Essa rede passou a pressionar o Governo argentino desde fora, pelos Estados Unidos, e desde dentro, pelo empoderamento dos atores locais, com o objetivo primordial de encontrar os desaparecidos. $\mathrm{Na}$ época não se falava, contudo, em responsabilizar indivíduos por desaparecimentos (SIKKINK, 2011, p. 64-66).

Entre a primeira demanda por responsabilização individual no interior do movimento argentino de direitos humanos, que é de 1980 e de 1983, a demanda por "julgamento e punição para todos os culpados" torna-se, no entanto, primordial (SIKKINK, 2011, p. 69). O que teria mudado em tão pouco tempo? Sikkink enumera alguns fatores: o relatório da CIADH sobre a Argentina, como antecipamos; a derrota do governo militar na Guerra das Malvinas; a má condução da guerra teria

2 Para um estudo sobre a origem e as circunstâncias do aparecimento da ideia de "graves violações de direitos humanos", ver Keys (2014). 
acarretado perda de legitimidade pelos militares e limitou-lhes as possibilidades de controlar a transição. Dois mecanismos de socialização teriam concorrido para o fim do regime autoritário argentino: a conformidade aos padrões da sociedade internacional, em decorrência do embaraço causado pelo relatório e das oportunidades abertas por ele, e a legitimidade, em razão dos custos domésticos gerados pelo uso do poder nas relações internacionais (SIKKINK; FINNEMORE, 1998, p. 903).

Em setembro de 1983, o governo militar argentino propôs uma autoanistia, e o candidato à presidência Raúl Alfonsín, em campanha, propôs anulá-la. Eleito, acabou, de fato, por revogá-la, e as Juntas Militares foram levadas a julgamento. O governo não pôde, contudo, controlar a precipitação de ações penais individuais. Por isso, Alfonsín teria aprovado a lei de obediência devida, bloqueando ações futuras, e Carlos Saúl Menem, seu sucessor, acabou por perdoar os membros das Juntas Militares (SIKKINK, 2011, p. 75-76). É nesse momento que os ativistas se voltam às instituições estrangeiras e regionais, acionando a CIADH e cortes de outros países, no que Sikkink aponta como uma versão judicial do seu modelo do efeito bumerangue. No plano doméstico, argumentam que o sequestro de crianças e a mudança da sua identidade não eram abrangidos pela anistia (SIKKINK, 2011, p. 77) e podiam, portanto, ser julgados e punidos.

Os direitos humanos possibilitam, então, ações quase judiciais, como as que correm na CIA$\mathrm{DH}$, e ações judiciais em cortes estrangeiras. Alguns aspectos do contexto podem explicar as inovações argentinas: o nível de repressão, muito maior que no Brasil, no Uruguai e no Chile, mas não tão intenso quanto na Guatemala, em que ela impossibilitou o ativismo local e, por conseguinte, o transnacional; a natureza da transição, feita com ruptura; a percepção e a exploração das oportunidades políticas pelos grupos locais; o pronto julgamento das Juntas Militares, que concorreu para a judicialização do processo; a estrutura do Judiciário argentino, com maior autonomia para os juízes e a possibilidade de particulares moverem ações penais (SIKKINK, 2011, p. 81-82). Mas a Argentina é uma referência importante para a formação da "cascata de justiça", sobretudo, porque participou na criação de dois dos principais mecanismos de accountability em justiça de transição: as comissões de verdade e as persecuções de altos oficiais e chefes de Estado por graves violações de direitos humanos (SIKKINK, 2011, p. 87-88).

Ativistas de direitos humanos que tiveram contato com a experiência argentina foram os propagadores das novas táticas e mecanismos de transição. Eles trabalharam na difusão das suas inovações - não necessariamente por aprovarem seus resultados -, e as difundiram também quando buscaram vias internacionais para estender ou reiniciar as persecuções. Foram pioneiros, ao lado dos chilenos, em explorar as oportunidades oferecidas pelas vias institucionais internacionais e em transformá-las em mecanismos de mudança (SIKKINK, 2011, p. 89-90). Essa difusão do modelo argentino aconteceu por meio de publicações, da mídia e do movimento de pessoas, especialmente em redes transnacionais envolvendo ONGs, mas também em governos e organizações internacionais (SIKKINK, 2011, p. 91).

Sikkink pontua que algumas mudanças foram necessárias para que houvesse uma "cascata de justiça". Para começar, o direito internacional passou a enfocar o indivíduo (SIKKINK, 2011, p. 98- 
99). ${ }^{3}$ Lembra, além disso, que a responsabilidade criminal individual estava presente há muito tempo na letra do direito internacional humanitário, mas - ressalva - o direito internacional humanitário e o direito internacional dos direitos humanos permaneceram separados até os anos 1980. Nos anos 1980, ativistas de direitos humanos, de fato, percebem que muitas graves violações de direitos humanos eram cometidas por Estados e grupos armados em conflitos internos, e que as Convenções de Genebra poderiam fornecer ferramentas para atribuir responsabilidade criminal individual nessas situações específicas (SIKKINK, 2011, p. 106). A figura proeminente nessa aproximação, segundo a autora, foi Aryeh Neier, à época, Diretor Executivo da Human Rights Watch (HRW). Neier teria reconhecido, no direito humanitário, a oportunidade de contornar o argumento dirigido aos grupos de direitos humanos de que eles eram parciais, somente criticando o Governo, e ele ainda lhe possibilitava ganhar alguma credibilidade na administração Reagan, refratária ao tema dos direitos humanos (SIKKINK, 2011, p. 106-107).

Estudando a corrente de Nuremberg à Haia mais detidamente, Sikkink conta que o primeiro a reclamar a criação de um tribunal penal internacional, propriamente, teria sido um jornalista da antiga Iugoslávia que, em 1991, lança um apelo com o título Nuremberg Now. Em 1992, a HRW chamou os Estados a estabelecerem um tribunal para julgar graves violações de direitos humanos e direito humanitário, recomendando a apuração da responsabilidade individual pelos crimes praticados nos Bálcãs. Neier teria influenciado a Human Rights Watch a propugnar por tribunais internacionais, em razão da sua reticência em relação aos julgamentos domésticos por graves violações de direitos humanos, que, na época, tinham lugar em 23 países, mas que, aos seus olhos, podiam criar ou aumentar a instabilidade (SIKKINK, 2011, p. 108-109). Ele pontua que a referência, claramente, era Nuremberg, e ela, ainda, seria reforçada dias depois, quando os meios de comunicação veicularam fotos dos campos de concentração em alusão ao Holocausto. O Conselho de Segurança estabelece uma Comissão de Especialistas liderada por Bassiouni, e, em 1993, Madeleine Albright, nova embaixadora dos Estados Unidos na ORGANIZAÇÃO DAS NAÇÕES UNIDAS (ONU), revela-se uma defensora incansável da criação de um tribunal para encaminhar o problema, tendo o Holocausto em mente. De resto, a maioria dos envolvidos no estabelecimento do TPII cita o mesmo precedente (SIKKINK, 2011, p. 110-112). É nesse mesmo momento que os argentinos tentam contornar o bloqueio das vias internas efetuado pela anistia. Por um lado, recorrem às vias internacionais e, por outro, propõem teses jurídicas inovadoras no Judiciário interno.

Tendo-se proposto analisar aquelas duas correntes que confluiriam para a "cascata de justiça”. Sikkink retoma, então, o papel do Judiciário argentino na construção de entendimentos com base no direito internacional a serem aplicados no plano interno e indica as condições estruturais que lhe permitiam elaborar essas teses, em especial, a possibilidade conferida a particulares de propor

\footnotetext{
3 Essa mudança, liderada por Cherif Bassiouni, teria começado no direito internacional penal dos anos 1940, e, para ela, concorreram, entre outros acontecimentos, a fundação do Instituto de Siracusa, a congregar estudiosos do direito internacional penal; a elaboração da Convenção contra a Tortura, afirmando a responsabilidade individual e a competência repressiva universal; a elaboração da Convenção contra o Apartheid, simultaneamente à Convenção contra a Tortura, afirmando o "apartheid" como crime contra a humanidade e retomando a linguagem penal do Tribunal de Nuremberg; a afirmação da obrigação internacional dos Estados de apurar a responsabilidade individual por desaparecimentos no sistema interamericano, com destaque para o caso Velásquez Rodríguez, de 1988 (SIKKINK, 2011, p. 101-106).
} 
ação penal e outras previsões do próprio direito argentino. Já as primeiras decisões do TPII, contemporâneas da decisão argentina que ela refere e pouco anteriores às decisões no caso Pinochet, não recebem de Sikkink a mesma atenção. Uma razão para isso pode ser ela considerar que os tribunais penais internacionais, bem como as cortes regionais, efetuam "julgamentos de direitos humanos", o que, em caso de avaliação positiva do fenômeno, dispensa qualquer outro parâmetro normativo a partir do qual se avaliem os efeitos dessa norma em matéria de direitos humanos.

Mas um olhar mais demorado para entendimentos e doutrinas criados pelo TPII tanto faz ver continuidades quanto faz suspeitar descontinuidades na linha que o liga a Nuremberg. Se nisso não nos enganamos, podemos, a partir da análise da jurisprudência do TPII, modular a segunda corrente que, segundo Sikkink, formou a "cascata de justiça". Pretendemos, no que se segue, mapear e analisar continuidades e descontinuidades entre o Tribunal de Nuremberg e o TPII. Propomos efetuá-lo a partir de entendimentos e análises manifestas nas primeiras decisões dos Juízos de primeira instância e do Juízo de Recursos do TPII a propósito dos crimes contra a humanidade, que, na literatura e, em alguma medida, na prática estatal e de órgãos de direitos humanos, confundem-se com as "graves violações de direitos humanos". Para tanto, começamos por apresentar, brevemente, o próprio Tribunal.

\section{A tensão entre direitos humanos e princípios penais no TPII: uma primeira incursão}

\subsection{Aspectos gerais do TPII}

O TPII foi criado em 1993, por resolução do Conselho de Segurança (S/Res/827), com fundamento no capítulo VII da Carta da ONU, para julgar graves violações das Convenções de Genebra de 1949 (artigo $2^{\circ}$ ), violações das leis e costumes de guerra (artigo $3^{\circ}$ ), genocídio (artigo $4^{\circ}$ ) e crimes contra a humanidade $\left(\operatorname{artigo} 5^{\circ}\right.$ ). Ele estabelece a responsabilidade criminal individual pela prática desses crimes (artigo $7^{\circ}, 1$ ), bem como afasta a imunidade de agentes públicos, incluídos chefes de Estado, quanto à defesa do cumprimento de ordens superiores (artigo. $7^{\circ}, 2$ e 4, respectivamente).

No que se refere à sua composição, o TPII conta com a Procuradoria, três Juízos de primeira instância, ou Trial Chambers, e um Juízo de Recursos, ou Appeals Chamber. Cada Juízo de primeira instância é composto por três juízes permanentes e no máximo seis juízes indicados para a lide; o Juízo de Recursos é composto por sete juízes permanentes, sendo cinco juízes do próprio TPII e dois do Tribunal Penal Internacional para Ruanda (TPIR), com o qual o Tribunal compartilhava o(a) Procurador(a) até 2007. O Tribunal foi criado, sobretudo, em uma "era dos direitos humanos", com competência para julgar graves violações de direito humanitário, das leis e costumes de guerra, crimes contra a humanidade e o crime de genocídio praticados no território da antiga Iugoslávia, a partir de 1991 (S/Res/808). ${ }^{4}$

\footnotetext{
4 Segundo o relatório do Secretário-Geral, a jurisdição temporal do TPIY teria sido definida em certa medida aleatoriamente, embora com duas preocupações em vista, a saber, descomprometer o Conselho de Segurança em relação ao tipo de conflito (internacional ou não internacional) para o qual o TPIY teria jurisdição e lhe reconhecer a jurisdição mais abrangente possível.
} 
Quando se conta a história do direito internacional penal, inscreve-se o TPII entre os esforços por apurar a responsabilidade criminal individual por graves violações de direitos humanos, com o progressivo afastamento das imunidades dos chefes de Estado e oficiais de alto escalão e o afastamento reiterado da excludente do cumprimento de ordens superiores (SIKKINK, 2011). Trata-se do primeiro tribunal competente para julgar crimes internacionais desde aqueles criados ao final da Segunda Guerra mundial - o Tribunal de Nuremberg e o Tribunal de Tóquio - e do primeiro tribunal propriamente internacional, caso consideremos seus antecessores como tribunais multinacionais (INTERNATIONAL CRIMINAL TRIBUNAL FOR THE FORMER YUGOSLAVIA, 1997). Ele é, em compensação, o primeiro de uma série. Com efeito, o TPII inaugura uma prática que a ONU incorpora ao seu repertório, a de efetuar a transição de um conflito para a paz mediante criação de um tribunal: na sequência do TPII foram criados o Tribunal Penal Internacional para a Ruanda (TPIR), em 1994, o Tribunal Penal Internacional (TPI) em 1998, a Corte Especial para Serra Leoa, em 2002, o Tribunal Especial para o Líbano, em 2005. ${ }^{5}$

Dado que, nos julgamentos do Tribunal de Nuremberg, o genocídio foi julgado no registro dos crimes contra a humanidade (artigo 6, c), o TPII é, ademais, o primeiro tribunal não nacional ${ }^{6}$ a julgá-lo como crime autônomo e elabora categorias, teses e entendimentos em matéria internacional penal para dar conta de fatos que pareciam desafiar o que lhe foi legado. Entre suas "criações" destacam-se, entre outras, a joint criminal enterprise, que primeiro aparece no caso Tadic; o estupro como meio para a prática de tortura, no caso Kunarac; o terrorismo como crime de guerra, no caso Galic. Já no famoso caso Tadic, o Tribunal tanto estende sua jurisdição aos conflitos não internacionais e afirma que crimes contra a humanidade podem ocorrer em tempos de paz, extrapolando, com isso, as previsões do seu próprio Estatuto, quanto amplia doutrinas herdadas dos tribunais que lhe precederam, como a da responsabilidade de comando, no caso Delalic.

Essas elaborações criativas tornam-se recorrentes na jurisprudência internacional, não infrequentes na jurisprudência de cortes nacionais, e a contribuição do TPII parece tão decisiva para o direito internacional penal que se corre o risco de esquecer que, em princípios dos anos 1990, não era necessário nem natural que o Tribunal fosse criado, menos ainda que, em meados da década, ele atuasse como de fato atuou. Tanto é assim que, antes das categorias, teses e entendimentos que o TPII cria buscando respostas para casos difíceis de solucionar nos estreitos limites do direito internacional positivo convencional, ele revigora a própria possibilidade de criar em matéria penal, no caso, em matéria internacional penal. Embora toda interpretação seja criação, e a competência dos tribunais internacionais para definir as suas próprias competências seja uma norma de direito internacional, o TPII logra criar categorias formais que extrapolam os rigores da norma penal, logo, a letra do seu Estatuto, e que inovam o corpo jurídico a ser aplicado por ele. Por isso, o Tribunal pode

\footnotetext{
5 Por acordo com a ONU ou por administração territorial, podem ser incluídos nesse rol os tribunais para o Kosovo, Timor Leste, Bósnia-Herzegovina e Camboja. Em geral se entende que esses seriam tribunais mistos ou internacionalizados, e adota-se, aqui, o critério de Schabas (2012) para considerá-los como tal, a saber, a autoridade competente para dissolvê-los não é estatal.

6 "Tribunal não nacional" designa, aqui, os tribunais internacionais e os tribunais multinacionais, a saber, o Tribunal de Nuremberg e o Tribunal de Tóquio. Não são considerados, portanto, os julgamentos nos territórios ocupados subsequentes ao Tribunal de Nuremberg ou Tribunal Militar Internacional.
} 
aparecer, de resto, destoando do padrão de atuação mais estrita, mais legalista, em uma palavra, que é a imagem comumente associada às cortes penais.

Quando o TPII começa a funcionar, a transição de países latino-americanos da ditadura à democracia estava em curso e se iniciava na África e na Ásia. Também se começou a negociar a instituição de uma jurisdição internacional penal permanente, e os trabalhos da Comissão de Direito Internacional (CDI) sobre a jurisdição material da futura corte ganharam ânimo. As primeiras decisões do TPII se referem constantemente aos relatórios e drafts de códigos elaborados pela Comissão de Direito Internacional, em que se discutia a jurisdição material de uma futura corte internacional penal permanente. Mais importante, nelas se forja uma relação singular e duradoura entre direitos humanos e direito internacional penal: ${ }^{7}$ o direito internacional penal será, com frequência, colocado em linha de continuidade com os direitos humanos, e, não raro, afirmar-se-á que um se torna parte do outro, i.e., que o direito internacional penal se torna parte, se não do direito internacional dos direitos humanos, ao menos dos direitos humanos em sentido lato.

Na prática judicial e também no campo da política, essa relação mostra-se, porém, marcada por tensões entre direitos humanos violados e princípios penais liberais, também eles consagrados como direitos humanos. Esse é o caso, entre outros, do princípio da legalidade, segundo o qual não há crime nem pena sem que uma lei o defina como tal, a norma penal tem de ser interpretada ou construída, restritiva e inequivocamente, e ela não pode ser aplicada retroativamente. Ocorre que, seja como norma de direito interno, seja como direito humano, i.e., como norma internacional, o princípio da legalidade impõe obstáculos ao poder estatal: no limite, protege o indivíduo contra o Estado. Se o TPII é, como ele se considera no caso Tadic, o primeiro tribunal propriamente internacional e representante da comunidade mundial, podemos afirmar, então, que ele também será o primeiro a responder, na prática, se os limites que se aplicam ao poder punitivo estatal e que têm sido justificados em razão da humanidade inerente à pessoa se estendem ao poder de punir exercido em nome da comunidade internacional ou em nome da humanidade.

\subsection{Os crimes contra a humanidade nas primeiras decisões do TPII: elementos para uma análise à luz de parâmetros de legalidade estabelecidos pelo Tribunal}

A jurisdição do TPII foi contestada desde antes do início do seu funcionamento. Em sua jurisprudência, a primeira resposta a esse questionamento foi dada no caso Tadic, em que se argumenta que o Tribunal é ilegítimo, porque, ao instituí-lo, o Conselho de Segurança teria extrapolado as competências que a Carta da ONU lhe confere. Nele argumenta-se, ademais, que é ilegal, por violar direitos e garantias reconhecidos ao acusado pela Declaração Universal e o Pacto de Direitos Civis e Políticos, que consagram o princípio da legalidade e o direito de ser julgado por tribunal imparcial e independente, com ampla possibilidade de se defender (artigos X e XI da Declaração; artigos 14 e 15, do Pacto). Não bastasse isso, os desafios postos pelo conflito nos Bálcãs à regulação internacional do

\footnotetext{
Sobre o assunto, ver Schabas (2008).
} 
uso da força constrangem o TPII a definir sua competência material, i.e., os crimes que lhe tocariam julgar. Afinal, as graves violações das Convenções de Genebra de 1949, criminalizadas no artigo 2 diziam respeito apenas aos conflitos internacionais ou também aos conflitos não internacionais? $\mathrm{E}$ as violações das leis e costumes de guerra, criminalizadas no artigo $3^{\circ}$ ? Pretendia-se que os crimes contra a humanidade teriam de ser cometidos "em conflito armado internacional ou interno"?

São essas algumas das questões que o Juízo de Recursos, formado pelos juízes Cassese, Li, Deschênes, Abi-Saab e Sidhwa, enfrenta em decisão interlocutória de 1995, a propósito do caso Tadic (INTERNATIONAL CRIMINAL TRIBUNAL FOR THE FORMER YUGOSLAVIA, 1995b). Nela, o Juízo de Recursos entende que o instituto jurídico das graves violações das Convenções de Genebra somente cobria conflitos internacionais, como consta, por sinal, da sua letra. Mas este não se aplicava às violações das leis e costumes de guerra. Nesse caso, para que um ato criminoso praticado em conflito não internacional pudesse gerar responsabilidade criminal individual de direito internacional, o Juízo listou algumas condições, a saber, o ato precisaria violar uma norma costumeira de direito internacional humanitário; atingir valores importantes e produzir consequências graves para as vítimas; e acarretar responsabilidade criminal individual por direito convencional ou costumeiro (para. 94).

No que se refere aos crimes contra a humanidade, o Juízo de Recursos se limitou, nessa decisão de 1995, a afastar o argumento da defesa de que eles precisavam estar ligados a crimes contra a paz ou a crimes de guerra e aquele segundo o qual a definição do Estatuto do TPII violava o princípio da legalidade (para. 139).

O Estatuto do TPII criminaliza os "crimes contra a humanidade" nos seguintes termos:

The International Tribunal shall have the power to prosecute persons responsible for the following crimes when committed in armed conflict, whether international or internal in character, and directed against any civilian population:

(a) Murder;

(b) Extermination;

(c) Enslavement;

(d) Deportation;

(e) Imprisonment;

(f) Torture;

(g) Rape;

(h) Persecutions on political, racial and religious grounds;

(i) Other inhumane acts.

Partindo desse texto, o Juízo de Recursos afirma que a exigência do nexo dos crimes contra a humanidade com os crimes contra a paz ou os crimes de guerra foi peculiar aos tribunais do pós-Segunda Guerra ${ }^{8}$ e reproduzida apenas na resolução da Assembleia Geral da ONU de 1946, que reafirma os princípios da Carta do Tribunal de Nuremberg como normas de direito internacional (A/Res/1/95).

\footnotetext{
8 Conforme o artigo $6^{\circ}$ da Carta de Nuremberg, "[...] the Tribunal established by the Agreement referred to in Article 1 hereof for the trial and punishment of the major war criminals of the European Axis countries shall have the power to try and punish persons who, acting in the interests of the European Axis countries, whether as individuals or as members of organizations, committed any of the following crimes: [...] (c) crimes against humanity - namely, murder, extermination, enslavement, deportation, and other inhumane acts committed against any civilian population, before or during the war, or persecutions on political, racial or religious grounds in execution of or in connection with any crime within the jurisdiction of the Tribunal, whether or not in violation of the domestic law of the country where perpetrated."
} 
Ele pondera que esse nexo não consta da Lei do Conselho de Controle, ou Control Council Law, n. 10, que regula os julgamentos a acontecer nos territórios ocupados pela Alemanha ${ }^{9}$ e é contemporânea da Carta do Tribunal de Nuremberg. Sua obsolescência seria, de resto, evidente, se se considerasse a Convenção contra o Genocídio, de 1948, e a Convenção contra o Apartheid de 1973, as quais proibiriam condutas típicas dos crimes contra a humanidade (para. 140). Enfim, e para desfazer aquela ligação, o Juízo de Recursos afirma, no caso, que o entendimento de que os crimes contra a humanidade não requerem vínculo com qualquer tipo de conflito armado era um costume internacional (para. 141). ${ }^{10}$

O Juízo não mostra, todavia, como esse costume se formou e fica, por isso, mais suscetível a considerações contrárias. Ele indica, por exemplo, a ausência do nexo com os crimes contra a paz ou os crimes de guerra na Lei do Conselho de Controle n. 10 e, procedendo por analogia, também na Convenção contra o Genocídio e na Convenção contra o Apartheid. A analogia parece, de fato, razoável, porque o genocídio e a perseguição por discriminação em razão de cor ou etnia são condutas típicas dos crimes contra a humanidade, e ambas as Convenções contemplam a instituição de uma jurisdição internacional penal. Em compensação, a resolução da Assembleia Geral reafirmando os princípios de Nuremberg é de 1946, apenas dois anos anterior à Convenção contra o Genocídio, e, como o próprio Juízo observou, nela se requer o nexo dos crimes contra a humanidade com os crimes contra a paz ou os crimes de guerra. A Lei do Conselho de Controle n. 10 de 1945 não o exige, mas ela se aplicava ao território alemão ocupado pelas potências aliadas e inclusive se refere à Carta do Tribunal de Nuremberg na definição da sua jurisdição.

É por elaborações e aproximações sucessivas que os crimes contra a humanidade ganham contornos mais claros no Tribunal. Cerca de duas semanas depois da decisão interlocutória do Juízo de Recursos no caso Tadic, o Juízo de primeira instância formado pelos juízes Jorda, Odio Benito e Riad manifesta-se sucintamente sobre o assunto, sem deixar de acrescentar alguns elementos ao debate. Em revisão da denúncia contra Nikolic, acusado de comandar um massacre em um campo de detenção na Bósnia, o Juízo corrobora o entendimento de que o requisito de prática do ato em um conflito armado, internacional ou interno, restringia uma norma costumeira; desde Nuremberg se reconheciam os crimes contra a humanidade como crimes autônomos (INTERNATIONAL CRIMINAL TRIBUNAL FOR THE FORMER YUGOSLAVIA, 1995a). O Juízo afirma, ademais, que os crimes contra a humanidade teriam três componentes: ataques dirigidos contra a população civil; ataques organizados e sistemáticos, i.e., não fossem obra unicamente de indivíduos isolados; e ataques que tivessem certa escala e gravidade.

A revisão da denúncia é efetuada com base nas Regras de Procedimento e Evidência do Tribunal, que dispõem mais detalhadamente, entre outras coisas, sobre os direitos e as garantias do acu-

\footnotetext{
9 Conforme o artigo II da Control Council Law n. 10, "[...] each of the following acts is recognized as crime: [...] (c) crimes against humanity. Atrocities and offenses, including but not limited to murder, extermination, enslavement, deportation, imprisonment, torture, rape, or other inhumane acts committed against any civilian population, or persecutions on political, racial or religious grounds whether or not in violation of the domestic laws of the country where perpetrated."

10 Nas palavras do próprio Juízo de Apelação, "[...] it is by now a settled rule of customary international law that crimes against humanity do not require connection to international armed conflict. Indeed, as the Prosecutor points out, customary international law may not require a connection between crimes against humanity and any conflict at all." (para. 141) (INTERNATIONAL CRIMINAL TRIBUNAL FOR THE FORMER YUGOSLAVIA, 1995b).
} 
sado e os modos de produção de prova. A revisão tem fundamento, mais especificamente, na regra 61, que a prevê para caso de não cumprimento de mandado expedido pelo TPII. No entendimento do Juízo de primeira instância, tratar-se-ia de um meio para lhe suprir a falta de "poder de polícia" e para permitir às vítimas ser ouvidas em público e ter uma parte na história.

Ela volta a ser usada, no início de 1996, no caso Msksic et al, também conhecido como caso Hospital Vukovar, em que Mskisc, Radic e Sljivancanin teriam transferido não combatentes do hospital para uma fazenda, onde executaram homens, mulheres e crianças, pelo que foram acusados de graves violações das Convenções de Genebra, violações das leis e costumes de guerra e crimes contra a humanidade (INTERNATIONAL CRIMINAL TRIBUNAL FOR THE FORMER YUGOSLAVIA, 1996b). Revisando a acusação de crimes contra a humanidade, o Juízo de primeira instância formado por Jorda, Odio Benito e Riad considera que o elemento do caráter generalizado ou sistemático do ataque contra a população civil tinha a finalidade de possibilitar distingui-los dos crimes de guerra. Essa colocação pode apontar para uma dificuldade posta pelo requisito de que o ataque seja praticado em conflito armado, que, a persistir, teria de ser interpretado em confronto com aqueles outros crimes previstos no Estatuto do Tribunal. O Juízo prossegue e considera, no entanto, que um ato que tenha ligação com um ataque desse tipo já se qualificaria como crime contra a humanidade, mesmo que fosse um ato individual e vitimasse uma única pessoa (para. 30).

Essa discussão mais técnica sobre os elementos dos crimes contra a humanidade avança pouco no caso Erdemovic, o primeiro concluído pelo Tribunal, mas nele se revelam elementos que - argumentamos - participariam na construção e informariam a interpretação desses crimes em outros casos do TPII e de outros tribunais penais. No caso Erdemovic, não se chega sequer a elaborar sobre os crimes contra a humanidade, porque o acusado confessa sua culpa pela execução de 10 a 70 homens transferidos de Srebrenica. Em decisão de 1996, o Juízo de primeira instância formado por Jorda, Odio Benito e Riad limita-se, então, a analisar a validade da confissão (INTERNATIONAL CRIMINAL TRIBUNAL FOR THE FORMER YUGOSLAVIA, 1996a). Mas, em meio a tantas ponderações a respeito do estado de necessidade, ou seja, da existência ou não de um dever de desobedecer a ordem superior, o Juízo afirma que,

[...] with regard to a crime against humanity, the Trial Chamber considers that the life of the accused and that of the victim are not fully equivalent. As opposed to ordinary law, the violation here is no longer directed at the physical welfare of the victim alone but at humanity as a whole (para. 19).

E prossegue:

Crimes against humanity are serious acts of violence which harm human beings by striking what is most essential to them. Their life, liberty, physical welfare, health, and or dignity. They are inhumane acts that by their extent and gravity go beyond the limits tolerable to the international community, which must perforce demand their punishment. But crimes against humanity also transcend the individual because when the individual is assaulted, humanity comes under attack and is negated. It is therefore the concept of humanity as victim which essentially characterizes crimes against humanity. (para. 28). 
A não equivalência entre a vida do criminoso e a das vítimas e a humanidade como vítima: eis o resumo do caso.

Os crimes contra a humanidade são abordados, mais tecnicamente e com maior parcimônia, em decisão de 1997 no caso Tadic (INTERNATIONAL CRIMINAL TRIBUNAL FOR THE FORMER YUGOSLAVIA, 1997). Nela, o Juízo de primeira instância, formado pelos juízes Kirk McDonald, Stephen e Vohrah, primeiro assinala que o TPII é, a rigor, o primeiro tribunal internacional, considerando que o Tribunal de Nuremberg e o Tribunal de Tóquio eram "multinacionais" e representantes de apenas parte da comunidade mundial (para. 1). Depois remonta ao mesmo Tribunal de Nuremberg para lembrar que os crimes contra a humanidade foram consagrados em sua Carta para punir aqueles que tinham cometido crimes que não podiam ser enquadrados como crimes de guerra, porque praticados pelos nazistas contra apátridas ou seus nacionais ou nacionais de seus aliados (paras. 619-620). No TPII, esses crimes contra a humanidade compreenderiam, conforme o Juízo, um ataque contra qualquer população civil, i.e., contra civis e pessoas fora de combate; em conflito armado, i.e., durante conflito armado internacional ou interno; generalizado ou sistemático, considerando política de Estado ou de organização; tendo o acusado conhecimento do contexto em que seu ato se insere (para. 626). Em respaldo ao seu argumento, o Juízo de primeira instância ainda compara a definição do Estatuto do TPII com a de outros documentos, como drafts de códigos preparados pela CDI e o Estatuto do TPIR (para. 627): com isso, ele consegue mostrar que a definição dos crimes contra a humanidade no TPII era mais restrita (para. 630).

Mas há um contrassenso nessa abordagem. Operando com elementos estranhos ao texto da norma consagrado no Estatuto do TPII sem descartar o conflito armado, o Juízo poderia restringir ainda mais os crimes contra a humanidade. Esse contrassenso é, todavia, aparente, dado que, na sequência, o Juízo de primeira instância do caso parece descartar o requisito do conflito para afirmar que a condição seria satisfeita, simplesmente, se o ato e o conflito não fossem não relacionados (paras. 633-634). No que se refere ao aspecto generalizado ou sistemático do ataque e à perseguição de uma política, o Juízo esclarece que ambos seriam elementos do "ataque dirigido contra qualquer população civil", por força da necessidade de distinguir atos típicos dos crimes contra a humanidade de atos isolados de indivíduos motivados unicamente por razões pessoais (paras. 649 e 653). Seguindo o Draft Code of Crimes against the Peace and Security of Mankind de 1996, da CDI (A/51/10), o Juízo fala, então, em "política de Estado, ou de uma organização, ou de um grupo" e ressalta que essa política não precisaria ser formal, podendo ser constatada a partir do modo dos ataques, se generalizados ou sistemáticos (para. 654). Assim, em sua lógica, os crimes contra a humanidade chocam a comunidade internacional por não serem atos isolados, mas visarem à população civil, e atos como estes somente poderiam ser praticados como parte de uma política para praticá-los.

Nessa decisão de 1997 ao caso Tadic, temos, pois, uma definição de crimes contra a humanidade significativamente diferente dos termos em que eles aparecem no Estatuto do TPII. Quando ela é proferida, o Tribunal para Ruanda já estava em funcionamento e as negociações do Estatuto do TPI estavam avançadas. A definição dos crimes contra a humanidade ao final do caso Tadic parece 
mais alinhada com esses diplomas legais, sobretudo os Estatutos do Tribunal para Ruanda e do Tribunal Penal Internacional, do que com o Estatuto do Tribunal para a antiga Iugoslávia.

Essa aproximação dos textos terá continuidade no caso Delalic. Em decisão de 1998, o Juízo de primeira instância, formado pelos juízes Karibi-Whyte, Odio Benito e Saood Jan, parte do princípio da legalidade para estabelecer parâmetros para o que ele assume ser uma "construção de estatutos penais". Então, ponderam que o princípio da legalidade se desdobra na exigência da definição do crime e da pena por lei; na proibição de aplicação de lei elaborada depois do fato, i.e., na proibição da retroatividade; na exigência da especificidade e não ambiguidade da norma (para. 402) (INTERNATIONAL CRIMINAL TRIBUNAL FOR THE FORMER YUGOSLAVIA, 1998). Afirmam que é assim no sistema penal interno de inúmeros países. Mas também ressaltam que, no plano internacional, não há um legislador mundial, e essa falta imprimiria uma marca própria ao princípio da legalidade no direito internacional penal. Não menos importante, no sistema penal internacional o princípio teria de equilibrar-se entre os direitos do acusado e a manutenção da ordem mundial (para. 404), o que significa dizer que ele não implica a prevalência dos interesses do acusado, como ocorre nos sistemas penais estatais.

O Tribunal para a antiga Iugoslávia estaria, assim, autorizado a construir "estatutos penais" ou "normas penais" e procederia à sua construção observando outros dois princípios, corolários da legalidade: a construção restritiva da norma penal e a sua não retroatividade. Como a norma penal se caracteriza, no entender dos juízes do caso, por infligir sofrimento ou a privação de liberdade (para. 408) ao indivíduo, é preciso que ela seja inequívoca e que a "intenção do legislador" seja manifesta (para. 409).

O Juízo não enfrenta, porém, algumas questões difíceis colocadas a partir da sua proposta. Pressupondo que o legislador a que ele se refere não é o próprio Tribunal, nem seus órgãos, a "intenção do legislador" teria de ser inferida ou construída, tomando por base tratados ou costumes internacionais. Como inferi-la de tratados e ignorar que, se os Estados, de fato, tivessem determinada intenção, teriam celebrado ou celebrariam um diploma manifestando a sua vontade e regulando a matéria ou situação? É, sem dúvida, mais fácil sustentar que se apreende a vontade formadora do costume internacional. Nessa hipótese, o Juízo poderia afirmar, com melhores razões, que infere a intenção a que a norma penal pretende dar efeito a partir de práticas reiteradas e convicções na obrigatoriedade de determinado comportamento. O problema, aqui, é que também o conteúdo da vontade manifestada, não raro, tem de ser inferido, e a vontade difere de um Estado para outro.

Em decisão de 2000, no caso Blaskic, o Juízo de primeira instância formado pelos juízes Jorda, Rodrigues e Shahabuddeen nomeará, enfim, alguns indicadores do que se entende por "caráter sistemático" para fins de enquadramento de uma conduta como crime contra a humanidade. Esses indicadores seriam a existência de um objetivo político, plano ou ideologia, o ataque ser perpetrado em larga escala ou haver ataques contínuos, o uso significativo de recursos públicos ou privados e o envolvimento de autoridades políticas ou militares de alto escalão (para. 203) (INTERNATIONAL CRIMINAL TRIBUNAL FOR THE FORMER YUGOSLAVIA, 2000). A existência de um "plano" poderia ser inferida, ao seu turno, do estabelecimento de estruturas políticas autônomas em qualquer nível; do conteúdo do programa político; da propaganda; da mobilização de forças armadas; da 
realização de ofensivas militares repetidas e coordenadas; de medidas discriminatórias; da escala dos atos de violência (para. 204). Seja como for, os crimes contra a humanidade não eram, no entender dos juízes de Instrução, ato de uma soberania criminosa, podendo ser praticados por organizações, gangues, ou grupos criminosos.

O Juízo remete outra vez ao Draft de 1996 elaborado pela CDI e afirma que o Estatuto do TPI recoloca a possibilidade de que atos criminosos praticados como parte de uma política não estatal configurem crimes contra a humanidade: o Estatuto do TPI fala, entretanto, em "Estado ou organização", tendo claramente retirado a menção a gangues ou grupos criminosos. Na prática, isso implicaria que atos praticados por grupos ou gangues não configuram crimes contra a humanidade para fins de direito internacional penal. Eles não deixam de ser crimes, apenas não são crimes internacionais.

Retomemos nesse ponto, então, a discussão. O Estatuto do TPII estabelece dois requisitos basilares para que os crimes contra a humanidade se configurem, a saber, os atos criminosos serem cometidos em conflito armado (internacional ou interno) e serem dirigidos contra qualquer população civil. Com base nas decisões estudadas, construímos o entendimento de que, em se tratando desses crimes, o requisito do conflito armado significa que os atos não podem ser não relacionados com o conflito armado, i.e., eles devem ter ocorrido entre o início e o término do conflito e no mesmo território em que ele acontece. Esse entendimento tem sentido em se tratando do Estatuto do TPII pela necessidade de que os crimes contra a humanidade se distinguissem tanto dos crimes comuns, cometidos em tempos de paz, quanto dos crimes de guerra, cometidos em conflitos armados.

No caso do Tribunal para a antiga Iugoslávia essa distinção é muito importante. Primeiro porque se entendeu, já no caso Tadic, que o assassinato, a tortura, o tratamento desumano, entre outros atos, praticados em conflito interno, poderiam configurar violações das leis e costumes de guerra. Depois, ela importaria porque, como se leu no caso Erdemovic, o TPII reconhece que a pena tem, primordialmente, função de retribuição e prevenção geral, ou deterrence, ficando a ressocialização do condenado em segundo plano. Essa separação entre as funções da pena teria, ademais, impacto na sua execução, dado que o condenado a cumprirá em país que se dispuser a recebê-lo, ou seja, em regra, longe do seu ambiente e da sua família.

Uma forma de separar crimes internacionais e crimes comuns é, justamente, especificar elementos contextuais sem os quais os primeiros não se configuram. $\bigcirc$ Tribunal para a antiga Iugoslávia o reconhece ao seu modo: quando afasta o requisito do conflito armado, passa a operar com a ideia de ataque generalizado ou sistemático e a política de Estado ou de organização ou de grupo criminoso. De fato, a maior parte do debate nas decisões analisadas consiste em saber se o ataque deve ser generalizado ou sistemático, cumulativa ou alternativamente; se somente cabe falar em política de Estado ou concebe-se uma política de organização para a prática; nesse caso, discute-se que tipo de organização poderia praticá-los. Diante da impossibilidade de alterar a norma penal, o Tribunal parece embutir, assim, requisitos estranhos à definição de crimes contra a humanidade do seu Estatuto no elemento "ataque direcionado contra qualquer população civil", ponderando que 
eles permitiriam distinguir atos criminosos do ponto de vista do direito internacional de atos de indivíduos com motivação exclusivamente pessoal.

Há, portanto, construção, mas não de uma norma penal: os crimes contra a humanidade já tinham sido previstos, afinal, na Carta do Tribunal de Nuremberg. Decerto, em Nuremberg nenhum acusado foi condenado unicamente por crimes contra a humanidade, com exceção da condenação de Baldur von Schirach, entre outras coisas porque a Carta os definia como conectados ou aos crimes contra a paz ou aos crimes de guerra. Como em Nuremberg, nos anos 1990, os crimes contra a humanidade renderam, em geral, penas mais longas, mas, ao seu turno, entendia-se que eles poderiam ser praticados em tempos de paz, como afirma o próprio Tribunal para a antiga Iugoslávia. $\mathrm{O}(\mathrm{s})$ movimento(s) de direitos humanos, e em especial os processos de transição para a democracia na América Latina, pode $(\mathrm{m})$ ajudar a entender não somente as escolhas e práticas institucionais, como também a saliência das graves violações de direitos humanos em geral e dos crimes contra a humanidade em particular. Daí a possibilidade explorada pelo TPII de condenar com fundamento em norma que os criminaliza, e unicamente nela. A construção empreendida pelo TPII é a de um texto normativo bastante diferente do texto-base. Essa construção não ocorre restritivamente, como o Juízo de primeira instância preconizara no caso Delalic. A norma não se aplica retroativamente, porque, como se tem reiterado, os crimes contra a humanidade eram norma internacional costumeira desde os julgamentos do pós-Segunda Guerra mundial, mas a observância desse parâmetro de legalidade para a construção de normas internacionais penais também pode ser questionada se olharmos para o conteúdo da norma, não apenas para o seu nome.

Nessa linha, poderíamos argumentar que teriam sido violados, então, alguns direitos humanos. Mas lembremos que, conforme o próprio Tribunal para a antiga Iugoslávia, nas decisões estudadas, o processo internacional penal deve equilibrar os interesses do acusado com a manutenção da ordem mundial; os crimes contra a humanidade atingem as vítimas e a humanidade ao mesmo tempo; por isso, a vida do acusado não seria equivalente à vida das vítimas. Por essas e outras razões, concluiríamos que, como disse o Juízo de primeira instância no caso Erdemovic, as garantias consagradas em diplomas de direitos humanos, de fato, não se aplicam aos tribunais penais internacionais como se aplicam aos Estados, e isso não apenas porque não há um legislativo mundial que criminalize condutas e lhes atribua penas: é também porque a interpretação das normas internacionais penais tem de buscar um equilíbrio entre os direitos do acusado, como proferiu o Juízo de primeira instância em decisão no caso Delalic, e os interesses das vítimas e da humanidade-vítima, cujas vida e ordem são prevalentes, como declarou o Juízo de primeira instância em Erdemovic.

\section{Considerações finais}

Neste artigo, propusemos identificar e pensar potenciais tensões entre direitos humanos e princípios penais, recuperando, na jurisprudência do TPII, uma discussão sobre o princípio da legalidade no direito internacional penal e avaliando se a construção dos crimes contra a humanidade pelo próprio TPII se adequaria a esse parâmetro. Nessa discussão, percebemos que a legalidade no direito 
internacional penal estaria centrada nas ideias de construção (interpretação) restritiva e inequívoca da norma penal e de não retroatividade (caso Delalic).

Estatuto do TPII estabelece dois requisitos para que os crimes contra a humanidade se configurem: os atos criminosos serem cometidos em conflito armado (internacional ou interno) e serem dirigidos contra qualquer população civil. Nas decisões estudadas, notamos que o TPII afasta o "precedente" de Nuremberg de que os crimes contra a humanidade requeriam nexo ou com os crimes contra a paz ou com os crimes contra a humanidade e constrói o entendimento de que, em se tratando de crimes contra a humanidade, o requisito do conflito armado significa que os atos não podem ser não relacionados com o conflito armado, i.e., eles devem ter ocorrido entre o início e o término do conflito e no mesmo território em que ele acontece. Na maior parte das decisões analisadas, o debate em torno dos crimes contra a humanidade consiste em saber, entretanto, se o ataque deve ser generalizado ou sistemático; se somente cabe falar em política de Estado ou concebe-se uma política de organização para a prática; nesse caso, discute-se que tipo de organização poderia praticá-los. Entendemos, por um lado, que o TPII seja pressionado pelo fato de que os elementos "ataque dirigido contra qualquer população civil, em um conflito armado" dificultariam distinguir os crimes contra a humanidade das violações das leis e costumes de guerra; mas também entendemos que se torna tanto mais difícil manter os contornos dos crimes quanto mais extensivas as interpretações judiciais.

No caso dos crimes contra a humanidade, a construção da norma penal não teria sido restritiva, conforme o princípio da legalidade tal qual entendido pelo Tribunal para a antiga Iugoslávia e consagrado no catálogo de direitos humanos. Percebemos, já pela jurisprudência do Tribunal para a antiga Iugoslávia, que a criação de outras jurisdições penais internacionais, sobretudo o Tribunal para Ruanda e o TPI, aparentemente desencadeou uma aproximação da definição de crimes contra a humanidade do Estatuto do TPII em relação à definição desses crimes nos novos tribunais: diante da impossibilidade de alterar a norma penal, o TPII teria embutido, p.e., requisitos estranhos à definição de crimes contra a humanidade do seu Estatuto no elemento "ataque direcionado contra qualquer população civil". De modo mais geral, também se nota, nessas primeiras decisões, que a busca por um equilíbrio entre os direitos do acusado e a manutenção da ordem, manifesta em Delalic (1998), e a não equivalência da vida do acusado e das vítimas, manifesta em Erdemovic (1996), seriam concepções aparentes e subjacentes aos trabalhos do Tribunal.

No que se refere à relação entre direitos humanos e princípios penais liberais, o Estatuto do TPI já se beneficiou de toda a construção do Tribunal para a antiga Iugoslávia e do Tribunal para Ruanda, bem como da elaboração das regras de evidência e procedimento sucessivamente revisadas no âmbito do TPII, em especial. Na jurisdição internacional penal permanente, a definição dos crimes contra a humanidade dispensa qualquer ligação com um conflito armado ou, como lemos em Nuremberg, qualquer ligação com outros crimes internacionais. Os elementos contextuais relevantes desses crimes no TPI são o caráter generalizado ou sistemático do ataque e a persecução de política de Estado ou de organização. Por um lado, essa definição pouco difere da definição com a qual ao final e ao cabo o Tribunal para a antiga Iugoslávia acabou operando; por outro, a apropriação da sua jurisprudência pela maioria do Juízo de instrução causa polêmica, p.e., no caso Situação da República do Quênia: segundo o 
juiz Hans-Peter Kaul, ela ampliaria os contornos dos crimes contra a humanidade por resumir a "perseguição de política de Estado ou de organização" à prova do caráter sistemático do ataque.

Cabe ponderar que, aparecendo em um caso pontual e a propósito de uma situação com centenas de mortes e milhares de torturados, como é a situação de violência pós-eleitoral de 20072008 no Quênia, os efeitos práticos dessas considerações não parecem relevantes em comparação com os bens jurídicos (ou valores) que se pretendem tutelar pelos crimes internacionais. Mas, no marco do Estatuto de Roma, a prerrogativa de exercer o poder punitivo internacional é dos Estados, e não do TPI, e o TPI é acionado quando o Estado se mostra indisposto ou incapaz de julgar crimes internacionais que são de sua competência, i.e., crimes de guerra, crimes contra a humanidade e genocídio. Nos termos do Estatuto de Roma, são indícios de indisposição do Estado, entre outros, a demora injustificada no processamento ou o processamento não ser independente e imparcial (artigo 17, 2, b e c). Considerando que em países de tradição jurídica continental ou romano-germânica, os direitos humanos são consagrados no rol constitucional de direitos fundamentais, incluídos aí os princípios penais e os direitos do acusado, o que aconteceria se um processo penal se demorasse no plano interno em razão de garantias processuais ou nele se chegasse a resultado indesejado? Por fim, parece-nos importante dar a conhecer tensões que não são apreendidas em abordagens mais lineares da relação dos direitos humanos com o direito internacional penal e que, também por isso, acabam podendo preservar o potencial crítico tanto dos direitos humanos em relação ao que podemos chamar de "garantismo" penal quanto desse garantismo penal em relação aos direitos humanos.

\section{Referências}

ARTHUR, Paige. How "transitions" reshaped human rights: A conceptual history of transitional justice. Human Rights Quarterly, v. 31, n. 2, p. 321-367, 2009.

FINNEMORE, Martha; SIKKINK, Kathryn. International norm dynamics and political change. International Organization, v. 52, p. 887-917, 1998.

INTERNATIONAL CRIMINAL TRIBUNAL FOR THE FORMER YUGOSLAVIA. Prosecutor v. Dragan Nikolic. Review of Indictment pursuant to Rule 61 of the Rules of Procedure and Evidence, IT-942-R61, 20 Oct. 1995a.

INTERNATIONAL CRIMINAL TRIBUNAL FOR THE FORMER YUGOSLAVIA. Prosecutor $v$. Drazen Erdemovic. Judgment, IT-96-22-T, 29 Nov. 1996a.

INTERNATIONAL CRIMINAL TRIBUNAL FOR THE FORMER YUGOSLAVIA. Prosecutor v. Dusko Tadic. Decision on the Defence Motion for Interlocutory Appeal on Jurisdiction, 02 Oct. 1995 b.

INTERNATIONAL CRIMINAL TRIBUNAL FOR THE FORMER YUGOSLAVIA. Prosecutor v. Dusko Tadic. Judgment, IT-94-1-T, 07 May 1997.

INTERNATIONAL CRIMINAL TRIBUNAL FOR THE FORMER YUGOSLAVIA. Prosecutor $v$. Msksic, Radic and Slivancanin. Review of Indictment pursuant to Rule 61 of the Rules of Procedure and Evidence, IT-95-13-R61, 03 Apr. 1996 b. 
INTERNATIONAL CRIMINAL TRIBUNAL FOR THE FORMER YUGOSLAVIA. Prosecutor v. Tihomir Blaskic. Judgment, IT-95-14-T, 03 Mar. 2000.

INTERNATIONAL CRIMINAL TRIBUNAL FOR THE FORMER YUGOSLAVIA. Prosecutor v. Zejnil Delalic et al. Judgment, IT-96-21-T, 16 Nov. 1998.

KECK, Margaret; SIKKINK, Kathryn. Activists beyond borders: advocacy networks in international politics. Ithaca-London: Cornell University Press, 1998.

KELLY, Tobias. This side of silence: human rights, torture, and the recognition of cruelty. Philadelphia: University of Pennsylvania, 2012.

KEYS, Barbara J. Reclaiming American virtue: the human rights revolution of the 1970s. Cambridge-London: Harvard University Press, 2014.

MÉGRET, Frédéric. À quoi sert la justice pénale internationale? Disponível em: <http://ssrn.org/ abstract $=2161053>$. Acesso em: 17 maio 2014 .

MORENO-OCAMPO, Luís. The Nuremberg parallel in Argentina. Journal of International Criminal Justice, v. 11, p. 357-359, 1990.

MOYN, Samuel. Human rights and the use of history. London; NewYork: Verso, 2014.

MOYN, Samuel. The last utopia: human rights in history. Cambridge; London: Belknap Press-Harvard University Press, 2010.

SCHABAS, William. Unimaginable atrocities: justice, politics, and rights at the war crimes tribunals. Oxford: Oxford University Press, 2012.

SIKKINK, Kathryn. The justice cascade: how human rights prosecutions are changing world politics. New York-London: W. W. Norton\&Company, 2011.

VEÇOSO, Fabia Fernandes Carvalho. Entre absolutismo de direitos humanos e história contextual: aspectos da experiência da Corte Interamericana de Direitos Humanos. 2012. Tese (Doutorado em Direito)-Universidade de São Paulo, São Paulo, 2012.

Data da submissão: 08 de outubro de 2015 Avaliado em: 28 de maio de 2016 (AVALIADOR A) Avaliado em: 28 de maio de 2016 (AVALIADOR B)

Aceito em: 04 de novembro de 2016 